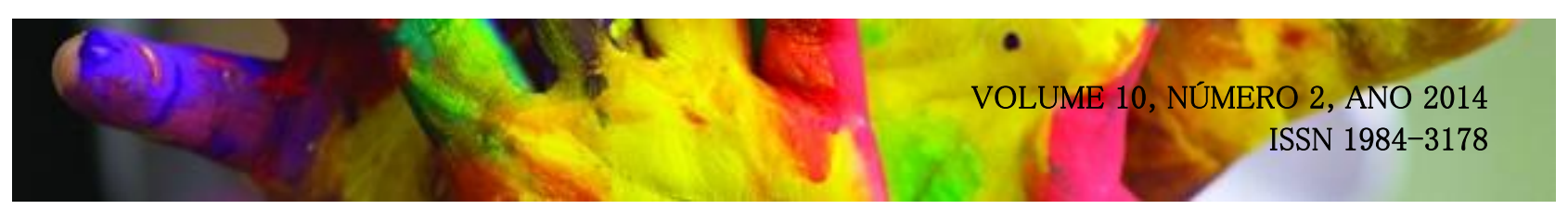

\title{
ARTES VISUAIS E NOVAS TECNOLOGIAS NA EDUCAÇÃO BÁSICA: ATIVIDADES POSSÍVEIS
}

\author{
DOI: http://dx.doi.org/10.5965/198431781022014033
}

Valéria Metroski de Alvarenga ${ }^{1}$

\section{RESUMO}

No presente artigo pretendemos apontar possíveis atividades que contemplem as Artes Visuais e as Novas tecnologias na Educação Básica. Antes, porém, discorreremos sobre a importância da inserção das mesmas no Ensino da Arte a partir das Diretrizes Curriculares Nacionais dos cursos de graduação em Artes Visuais e dos Parâmetros Curriculares Nacionais de Arte. Também utilizaremos textos sobre esse tema escritos por Santaella (2007), Pimentel (2011), Martins (2007), Bertoletti (2010) e Loyola (2009). Posteriormente, apresentaremos dados de uma entrevista realizada com professores de Artes Visuais que lecionam no Estado de Santa Catarina sobre como eles veem as novas tecnologias e como eles as utilizam na sala de aula. Por fim, apresentaremos diversas possibilidades de uso das novas tecnologias nas aulas de arte na Educação Básica, com foco na

linguagem visual e audiovisual (fotografia, cinema, vídeo-arte, stop motion, redes sociais, programas de manipulação e criação de imagem, aplicativos e museus virtuais). Temos como objetivo auxiliar professores de Artes Visuais com ideias que podem ser desdobradas e/ou adaptadas de diversas formas. Trabalhamos com a noção de hipertexto, por esse motivo disponibilizaremos muitos links de vídeos e de sites para que a leitura deste artigo seja direcionada e/ou ampliada conforme o interesse do leitor.

Palavras-chave: Artes Visuais. Novas Tecnologias. Educação básica. Atividades possíveis em sala de aula.

\begin{abstract}
This article seeks to identify possible activities that address the Visual Arts and New Technologies in Primary Education. First, however, we will discuss the importance of integrating new technologies in art education from the National Curriculum Guidelines for undergraduate courses in Visual Arts and the National Curricular Parameters Art. Subsequently, we present data from an interview conducted with teachers of Visual Arts in the State of Santa Catarina on how they see the new technologies and how to use it in the classroom. Finally, we will point out several possibilities of using new technologies in art classes in basic education, focusing on visual and audiovisual language. We as assisting teachers of Visual Arts with ideas that can be deployed and / or adapted in
\end{abstract}

1

Universidade do Estado de Santa Catarina (UDESC); Mestranda em Artes Visuais na linha de pesquisa Ensino da Arte; Licenciada em Artes Visuais pela UFPR; 


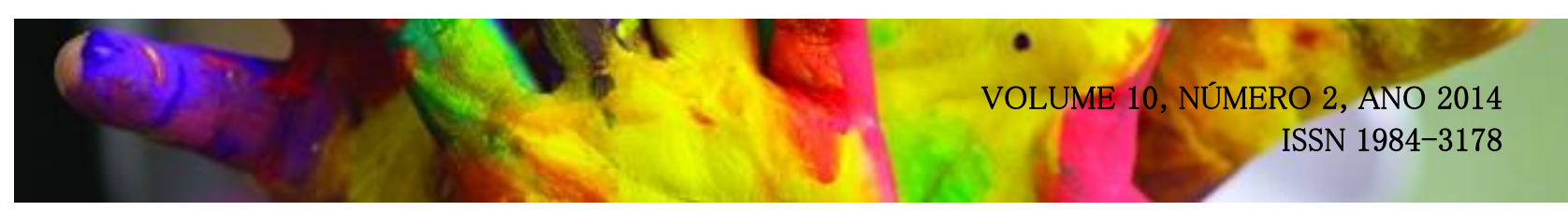

various forms goal. Discuss possible activities on photography, film, video art, stop motion, social networks, manipulation and imaging programs, applications, and virtual museums.

Keywords: Visual Arts. New Technologies. Basic education. Art teacher. Possibilities for activities in the classroom.

\section{INTRODUÇÃO}

O que são as novas tecnologias? Qual a importância do seu uso nas aulas de arte? Quais as orientações de diretrizes, parâmetros e propostas curriculares sobre esse tema? Essas são as questões norteadoras que permeiam o primeiro tópico deste artigo. Para respondermos tais perguntas, utilizaremos textos escritos por Santaella (2007), Martins (2007), Pimentel (2011), Bertoletti (2010) e Loyola (2009). Também utilizaremos o Parecer das Diretrizes Curriculares Nacionais para os cursos de graduação em Artes Visuais (2007) e os Parâmetros Curriculares Nacionais de Arte (1998).

No segundo tópico partimos de duas questões: como os professores de arte utilizam as novas tecnologias? Eles as veem como algo positivo? Com o intuito de responder essas questões, apresentaremos uma entrevista realizada junto ao Programa de Pós-Graduação em Artes Visuais da UDESC com 20 professores que lecionavam arte em Santa Catarina no ano de 2013. Tal pesquisa ocorreu durante a disciplina do mestrado e doutorado intitulada "Arte, Tecnologia e Formação docente", a qual foi ministrada pela professora doutora Maria Cristina Rosa Fonseca da Silva.

Por fim, no terceiro tópico, exibiremos algumas atividades possíveis utilizando as novas tecnologias no ensino de arte, especialmente nas aulas de Artes Visuais. Apresentaremos sugestões de atividades com fotografia, cinema, vídeo-arte, stop motion, museus virtuais, redes sociais, programas de criação e manipulação de imagens e aplicativos. Temos como base o conceito de hipertexto, o qual possibilita uma infinidade de relações com outros textos, por esse motivo colocamos uma grande quantidade de links com sugestões de vídeos e sites.

Nosso objetivo é conhecer como os professores de arte que atuam na educação básica veem e utilizam as novas tecnologias na sala de aula e auxiliá-los a propor atividades artísticas utilizando algumas das possibilidades que as mesmas oferecem. 


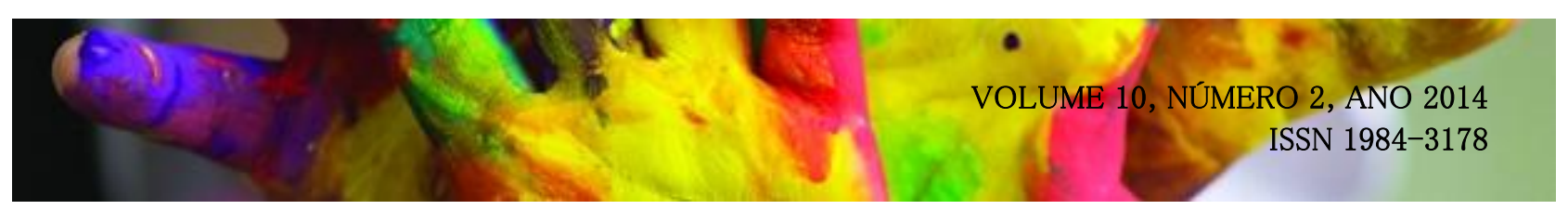

\section{NOVAS TECNOLOGIAS E ENSINO DE ARTE}

O que são as novas tecnologias? "Tecnologias contemporâneas, novas tecnologias, novos meios, tecnologias digitais são diversas as definições terminológicas atribuídas ao fenômeno do emprego da tecnologia na cultura contemporânea." (LOYOLA, 2009, p.1). Compreendemos, portanto, que existem várias nomenclaturas além das 'novas tecnologias' para denominar a mesma coisa. Todavia, neste artigo, manteremos o termo inicial e focaremos nas artes tecnológicas.

No artigo "As imagens no contexto das estéticas tecnológicas" escrito por Santaella (2007), são abordados os estágios evolutivos da imagem tecnológica. Esta autora, ao invés de utilizar o termo artes tecnológicas, utilizará "estéticas tecnológicas", as quais não se encontram apenas nas obras de arte ligadas ao sistema artístico contemporâneo, pois as:

(...) estéticas tecnológicas podem se fazer presentes em publicidades, designs de hipermídia, vinhetas de televisão, filmes documentários, efeitos especiais no cinema, nas novas formas híbridas das imagens em movimento, na moda, nas sonoridades circundantes e, especialmente, nas infinidades de portais, sites, blogs, de que o ciberespaço está povoado ou ainda nas telinhas de um celular que nos seduz com seus ícones animados e sons, com o acabamento de sua forma e superfície, com a sutileza dos seus minúsculos botões. (SANTAELLA, 2007, p. 2).

Vemos, portanto, que as novas tecnologias estão cada vez mais presentes nas nossas vidas e hoje não "sabemos" mais viver sem elas. Porém, não utilizaremos o termo que Santaella (2007) adotou, a saber: estéticas tecnológicas e nem comentaremos sobre a evolução da imagem através da tecnologia, pois este não é o foco deste artigo. Abordamos estes pontos apenas para evidenciar a abrangência das novas tecnologias e como estas não se aplicam apenas a produção/recepção artística mais restrita. Nosso objetivo consiste em abordar as novas tecnologias mais relacionadas ao ensino de arte.

“A tecnologia digital propicia novas formas de pensar e fazer arte." (PIMENTEL, 2011, p. 766). Considerando essa perspectiva, também precisamos encontrar novas formas de ensinar arte. Nesse sentido, devemos explorar/propor atividades com os alunos utilizando as novas tecnologias e também apresentar obras de artistas contemporâneos que trabalham com as mesmas ${ }^{2}$. Porém,

\footnotetext{
2 "Vários artistas passaram a usar o espaço da internet para suas criações, fazendo surgir a web arte, que é a arte feita exclusivamente para e na internet. Alguns artistas e críticos utilizam o termo net art para designar, de
} 


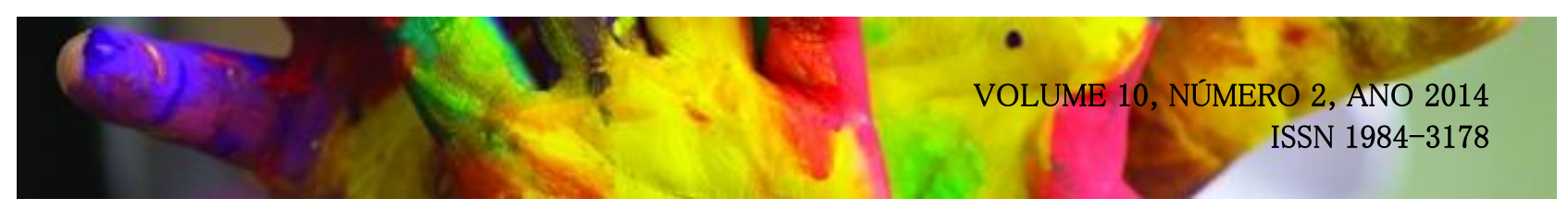

(...) os alunos precisam entender a natureza dos instrumentos de arte e os meios de escolha. Isso significa que é importante que façam exercícios para conhecer programas de tratamento de imagem, por exemplo, mas é essencial que pensem seu trabalho como sua própria produção artística, e não somente usem os recursos desses programas aleatoriamente. (PIMENTEL, 2011, p. 769).

Para que o processo de ensino-aprendizagem de arte, mediado pelas novas tecnologias, não seja algo 'vazio' é necessário que o professor tenha uma boa formação, tanto inicial quanto continuada, para poder proporcionar uma educação de qualidade aos discentes.

Existem orientações curriculares nacionais para que o professor de Artes Visuais tenha acesso e aborde questões referentes às novas tecnologias tanto na formação inicial, através das Diretrizes Curriculares Nacionais (DCN) para os cursos de graduação em Artes Visuais, quanto nos documentos norteadores do ensino de Arte, a saber: nos Parâmetros Curriculares Nacionais de Arte (PCN-Arte). Apresentaremos alguns aspectos referentes às novas tecnologias nesses documentos.

No que se refere à formação do professor de Artes Visuais, o Parecer das Diretrizes Curriculares Nacionais de graduação para essa linguagem artística aponta que tais cursos devem estar atentos "às tecnologias de produção e reprodução visual, de novas demandas de mercado e de sua contextualização marcada pela competição e pela excelência nas diferentes modalidades de formação profissional (...).” (Parecer DCN, 2007, p. 4).

Entendemos, portanto, que o futuro professor precisa ter um bom referencial teórico e prático, assim como disciplinas que possibilitem tanto o conhecimento das novas tecnologias quanto o ensino das mesmas através de inovações no processo ensino-aprendizagem por meio da arte. "É primordial, por parte dos professores e das instituições educacionais a busca de novos caminhos para a construção de conhecimentos enredados com a realidade em que vivemos." (BERTOLETTI, 2010, p. 3). Nesse sentido, o currículo das licenciaturas em Artes Visuais ${ }^{3}$ precisa proporcionar esse conhecimento ainda na formação inicial do professor de arte:

“Os conteúdos curriculares do curso de graduação em Artes Visuais, na modalidade

forma mais abrangente, trabalhos que possam estar em rede, mas não necessariamente na web". (LOYOLA, 2009, p.28 - itálico nosso).

${ }^{3}$ As artes visuais, além das formas tradicionais (pintura, escultura, desenho, gravura, arquitetura, artefato, desenho industrial), incluem outras modalidades que resultam dos avanços tecnológicos e transformações estéticas a partir da modernidade (fotografia, artes gráficas, cinema, televisão, vídeo, computação, performance). (PCN-Arte, 1998, p. 45). 


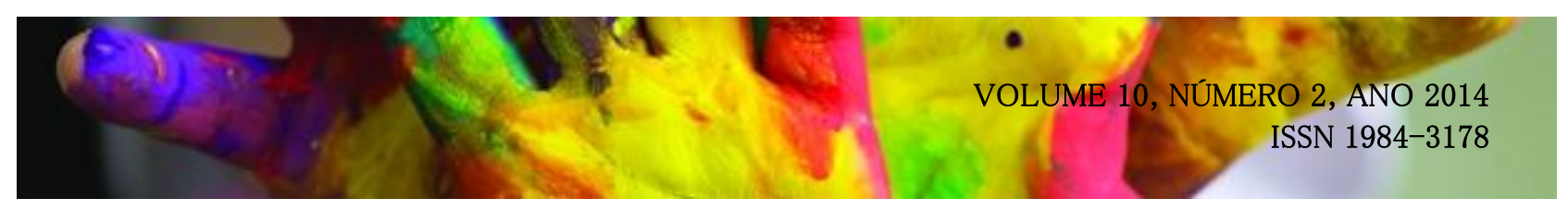

licenciatura, devem satisfazer também ao disposto na Resolução CNE/CP $n^{\circ}$ 1/2002, publicada em 9/4/2002, litteris: (...) VI - o uso de tecnologias da informação e da comunicação e de metodologias, estratégias e materiais de apoio inovadores." (Parecer DCN, 2007, pp. 5-6).

No que se refere ao professor de arte que já está atuando, os PCN-Arte incentivam o docente a utilizar as novas tecnologias nas suas aulas. Na parte que trata sobre Expressão e comunicação na prática dos alunos em Artes Visuais é sugerido que, entre outras possibilidades de trabalho, os alunos experimentem/utilizem “outros meios (máquinas fotográficas, vídeos, aparelhos de computação e de reprografia)" (PCN-Arte, 1998, p. 46) como forma de conhecer/pesquisar técnicas artísticas diversas.

Assim, pois, vemos que as novas tecnologias estão presentes em documentos norteadores, além de já fazer parte da vida de muitos alunos desde a mais tenra idade. E as próprias escolas, em geral, já possuem laboratórios de informática, Datashow, televisão, entre outros recursos tecnológicos. Vimos que os PCN-Arte e o Parecer das DCN dos cursos de graduação em Artes Visuais sugerem que as novas tecnologias sejam utilizadas:

Mas, mesmo diante desta realidade, as tecnologias de informação e comunicação, parecem
distantes da prática educacional. A arte contemporânea, bem como as tecnologias digitais,
mais especificamente o computador e a internet, mostram-se tímidas, ou mesmo, inexistentes,
dentro das propostas educacionais em arte ou do próprio conteúdo programático.
(BERTOLETTI, 2010, p. 1).

Tal problema advém tanto da infraestrutura dos colégios quanto da formação docente. No que se refere a esta última, Bertoletti (2010), fazendo referência a Barbosa (2005), afirma que o professor precisa dominar e conhecer no mínimo três possibilidades de relação entre as novas tecnologias/tecnologias digitais e o ensino da arte, a saber:

Como ferramenta: softwares de criação e produção de imagens. Como Pesquisa: diacrônica sites de arte, visita virtual em rede, e sincrônica - instantânea e virtual (Web Art). Como Linguagem: manifestações artísticas exclusivas das tecnologias digitais. (BERTOLETTI, 2010, p.10 - itálico nosso).

Concordamos com os requisitos necessários acima apontados, porém, como dito acima, sabemos que as dificuldades vão desde a formação do professor até questões de infraestrutura da própria escola. No entanto, sabemos que muitos professores de arte, apesar dos obstáculos, já estão fazendo uso das novas tecnologias nas suas aulas, tal como veremos nos comentários dos docentes entrevistados no Estado de Santa Catarina. 


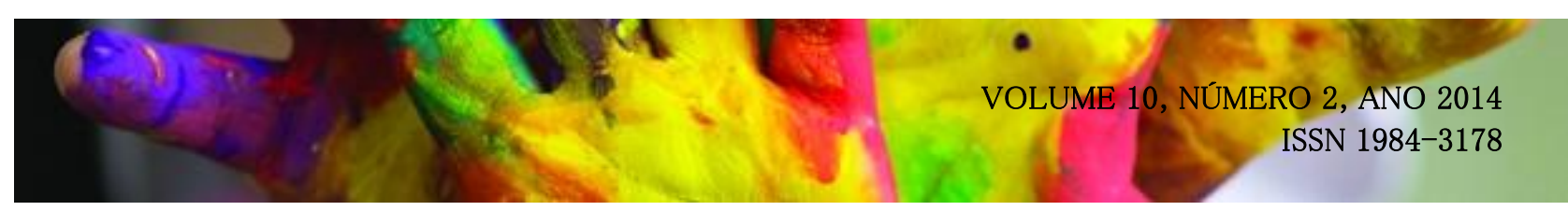

\section{COMO OS PROFESSORES DE ARTE UTILIZAM AS NOVAS TECNOLOGIAS NA SALA}

\section{DE AULA?}

As novas tecnologias estão cada vez mais presentes na sala de aula. Loyola (2009) afirma que:

Com a implementação de tecnologias nas escolas, a urgência em saber aplicá-las e lidar de forma crítica com os equipamentos e com as informações veiculadas torna-se imprescindível para o professor nas atividades em Arte na atualidade. Trabalhar as imagens estáticas e em movimento, assim como o áudio torna-se cada vez mais fácil e essa realidade configura-se em possibilidades de criação e de intervenções nas imagens, no áudio e em diversas outras atividades que podem ser planejadas e desenvolvidas pelo professor de Arte. (LOYOLA, 2009, p. 33).

Com base nessa afirmação, perguntamo-nos: os professores formados em Artes Visuais que atuam na Educação Básica fazem uso das novas tecnologias na sala de aula? Em caso afirmativo, como isso ocorre? Para responder tais questões, realizamos uma pesquisa com vinte (20) professores de Artes Visuais que lecionavam no Estado de Santa Catarina sobre o uso das novas tecnologias nas aulas de arte no ano de $2013^{4}$. Dos 20 entrevistados, oito (8) se formaram antes dos anos 2.000 e doze (12) após este período. Um (1) era mestre, treze (13) possuíam especialização e seis (6) só tinham graduação. Os professores entrevistados atuavam com turmas que iam desde o Ensino Fundamental I ( $1^{\circ}$ ao $5^{\circ}$ ano $)$ e Ensino Fundamental II ( $6^{\circ}$ ao $9^{\circ}$ ano $)$ até o Ensino Médio.

Perguntamos a esses professores se suas escolas haviam sido contempladas com as novas tecnologias. $95 \%$ do total responderam afirmativamente. A maioria afirmou que suas escolas possuíam laboratório de informática e Datashow. Uma professora comentou que "todas as escolas em que eu trabalho, e acredito que da Rede, tenham a sala informatizada, mas com computadores muito sucateados. Dispomos daquele equipamento que todas as escolas também receberam que foi um multimídia, com computador e projetor acoplados.” Alguns professores apontaram dificuldades sobre o uso dos laboratórios de informática, tal como: "a sala de informática não apresenta espaço adequado e não possui computadores suficientes para o número de alunos.” Nessa mesma linha de pensamento, outra professora relata que "o grande problema é estrutural. Falta estrutura de mais equipamentos na escola, pois uma sala informatizada é pouco para todos os professores e todas as

\footnotetext{
4 Pesquisa realizada pelos discentes da disciplina de mestrado e de doutorado do Programa de Pós-Graduação em Artes Visuais da Universidade do Estado de Santa Catarina (UDESC) intitulada “Arte, Tecnologia e Formação Docente", ministrada pela Professora Doutora Maria Cristina da Rosa Fonseca da Silva.
} 


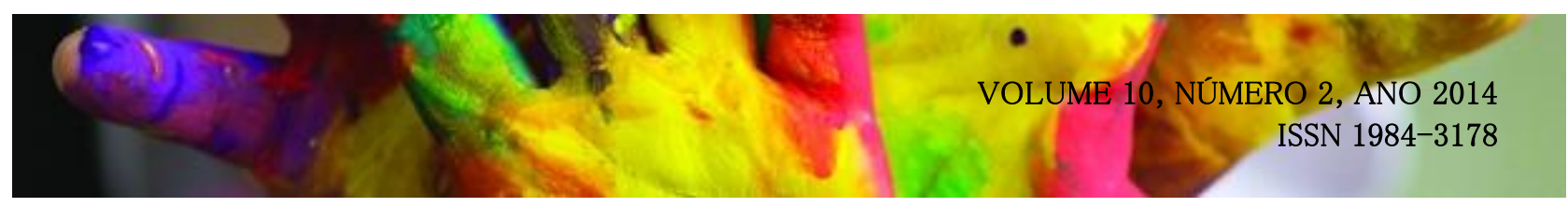

turmas. Internet de qualidade, que se possa acessar sites de museus, vídeos, etc.”

Posteriormente, perguntamos se eles faziam uso de algum recurso referente às novas tecnologias na sala de aula e $95 \%$ dos entrevistados responderam afirmativamente. Ressaltamos que, do total, 60\% dos entrevistados afirmaram que utilizavam Datashow, computador (tablets, notebooks, sala de informática) nas aulas de arte. Além desses equipamentos, alguns professores comentaram que utilizavam televisão, máquina de xerox, câmera fotográfica, lousa digital e celular.

Quando perguntamos se as novas tecnologias contribuíram positivamente para o ensino da arte, 95\% dos entrevistados responderam de modo afirmativo. Segundo uma professora "é inimaginável pensar o ensino de arte sem estes dois eixos: passeios virtuais em museus e imagens virtuais/digitais", outra afirmou que "para mim, o que elas mais auxiliam é no acesso às imagens (e veículo das mesmas) e no acesso às informações", outro ainda comentou que as novas tecnologias auxiliaram "na variedade de imagens, facilidade para visualizar obras, tornar mais atrativo e dinâmico o processo de ensino aprendizagem, um recurso que atrai pela sua diversidade”. Uma professora apesar de ter respondido afirmativamente, apontou um problema em relação a sua própria formação, a saber: "encontro algumas dificuldades quando penso em realizar algum trabalho como desenvolvimento de vídeos com os alunos, por não ter conhecimento suficiente dos programas utilizados."

Realizamos, ainda, a seguinte pergunta aos professores de Artes Visuais entrevistados: "Que tipo de materiais, programas ou sites você utiliza na Internet para planejar ou mesmo apresentar aos alunos nas aulas de arte?", com base nas respostas construímos a tabela abaixo:

Tabela 1. Sites e programas citados pelos entrevistados

SITES E PROGRAMAS CITADOS PELOS PROFESSORES

NÚMERO

ENTREVISTADOS

DE VEZES

Site de museus (diversos)

Site de artistas (diversos)

Itaú cultural

Disponível em:

http://novo.itaucultural.org.br/ Acesso em:

09/06/2014.

Wikipédia (diversos)

Movie Maker

Disponível em:

http://www.baixaki.com.br/download/windo 
ws-movie-maker.htm Acesso em:

06/06/2014.

\section{Google imagens}

Disponível em:

http://www.google.com.br/imghp?hl=pt-PT

Acesso em: 10/06/2014.

Museus virtuais (diversos)

\section{Brasil Escola}

Disponível em:

http://www.brasilescola.com/ Acesso em:

06/06/2014.

\section{Arte na Escola}

Disponível em: http://artenaescola.org.br/

Acesso em: 07/06/2014.

\section{Photoshop}

Disponível em:

http://www.baixaki.com.br/download/adobe

-photoshop.htm Acesso em: 04/06/2014.

\section{Gimp}

Disponível em:

http://www.baixaki.com.br/download/gimp.

htm Acesso em: 04/06/2014.

Youtube (diversos)

Art Project - Google cultural institute

Disponível em:

http://www.google.com/culturalinstitute/asset-

viewer/italy-grateful-to-

france $/ 5 \mathrm{gGMtuXsm} 8 \mathrm{zgkQ}$ ?projectId=art-project

Acesso em: 19/06/2014.

\section{Revista Nova Escola}

Disponível em:

http://revistaescola.abril.com.br/ Acesso em:

10/06/2014.

\section{Atividades educativas}

Disponível em:

http://www.atividadeseducativas.com.br/

Acesso em: 10/06/2014.

\section{Escola games}

Disponível em:

http://www.escolagames.com.br/ Acesso

em: 10/06/2014.

\section{Info educação}

Disponível em:

http://www.infoeducacao.com.br/sistemas- 


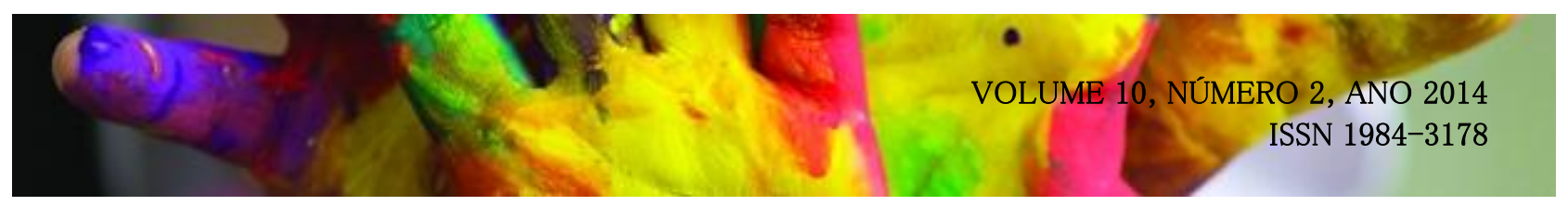

gestao-escolar/info-educacao.html Acesso

em: 11/06/2014.

\section{Mais educação}

Disponível em:

http://portal.mec.gov.br/index.php?option=c

om_content\&view=article\&id

$=16690 \&$ Itemid $=1113$

\section{Power point}

Disponível em:

http://www.baixaki.com.br/download/micro

soft-powerpoint.htm Acesso em:

10/06/2014.

\section{Tux Paint}

Disponível em:

http://www.baixaki.com.br/download/tux-

paint.htm Acesso em: 10/06/2014

Fonte: elaborado pela autora com base nas respostas dos professores entrevistados

Por fim, quando perguntamos como eles utilizam as novas tecnologias, constatamos que muitos professores as utilizam apenas como forma de reprodução de imagens. Segundo alguns deles, a visualização de obras e filmes ficam maiores através do Datashow e é mais fácil acessá-las através da internet. Segundo uma professora, esse fato "torna a aula mais atrativa". Enquanto que alguns professores apontaram que utilizam as novas tecnologias de forma mais efetiva do que 'contemplativa'. Uma professora disse que realiza "visitas a museus virtuais, produção de vídeo e interação com arte virtual", outra afirmou que trabalhou stop motion com os alunos e uma afirmou ter trabalhado com vídeo-arte. Alguns professores comentaram que realizam trabalhos com fotografia e manipulação de imagem no computador.

A partir do exposto, observamos que alguns professores já começaram a incorporar as novas tecnologias de forma mais concreta nas aulas de arte, porém muitos ainda utilizam as mesmas mais como veiculação da imagem. Concordamos que as novas tecnologias facilitaram o acesso as imagens, porém aquelas permitem uma infinidade de possibilidades, tal como alguns entrevistados já apontaram. Foi pensando nisso que enumeramos algumas atividades que abrangem as artes visuais e as novas tecnologias, as quais foram realizadas pela autora e/ou relatadas pelos professores entrevistados.

Ressaltamos que não pretendemos apresentar o surgimento das novas tecnologias e/ou a 


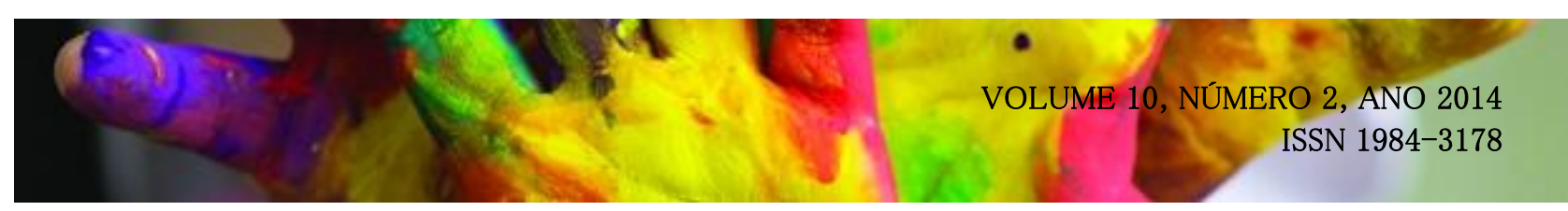

especificidade de cada meio. Nosso objetivo é relatar experiências e incentivar o maior uso das novas tecnologias por parte dos professores de arte, principalmente os de Artes Visuais que lecionam na educação básica. Por esse motivo apontaremos algumas atividades possíveis. Como estas estão, em geral, vinculadas ao computador e a internet, vejamos porque estes dois meios são importantes, segundo Loyola ${ }^{5}$ (2009):

O computador é uma ferramenta de informação e comunicação, assim como um instrumento para a auto-expressão e para a construção do conhecimento. A internet, com o seu desenvolvimento e popularização, assume cada vez mais características de participação e colaboração, com tecnologias que viabilizam a criação e a interação com obras de arte em ambientes virtuais e se configura como mais um espaço para atividades e pesquisas no ensino/aprendizagem. A interatividade propicia a experimentação, favorece a construção de conhecimento e amplia o campo de recursos pedagógicos para o ensino de Arte. (LOYOLA, 2009, p. 11).

Além do computador e a internet outros meios que podem ser utilizados para realização de atividades com as novas tecnologias na sala de aula são: o celular, a câmera fotográfica, a filmadora, a impressora e a máquina de xerox.

\section{NOVAS TECNOLOGIAS E ARTES VISUAIS: ALGUMAS ATIVIDADES POSSÍVEIS}

A arte contemporânea tem se utilizado cada vez mais das novas tecnologias e os alunos, na sua grande maioria, tem acesso a esses meios. Pensando nisso, tentamos aliar o interesse dos alunos por esses materiais com o ensino da arte focando e abordando a produção artística contemporânea. Logo abaixo, apresentaremos, de forma sucinta, algumas atividades possíveis que relacionam Artes Visuais e Novas tecnologias na sala de aula. Grande parte dessas atividades foi realizada pela autora do presente artigo juntamente com alunos do Ensino Fundamental II e do Ensino Médio entre os anos de 2009 e 2013 em colégios públicos. Algumas propostas de atividades estão baseadas no relato dos professores de Artes Visuais entrevistados.

Exibiremos sugestões de atividades com (1) fotografia, (2) cinema, (3) vídeo-arte, (4) stop motion, (5) museus virtuais, (6) redes sociais, (7) programas de criação e manipulação de imagens e (8) aplicativos. E, na medida do possível, indicaremos sites e locais onde o leitor pode obter mais

No final da dissertação me adicione.com Loyola (2009) disponibiliza uma grande quantidade de links sobre sites, blogs, vídeos que fazem referência a Arte, Cultura, Ensino, etc. Para acessá-los, veja o link do trabalho dele que a autora disponibilizou nas referências. 


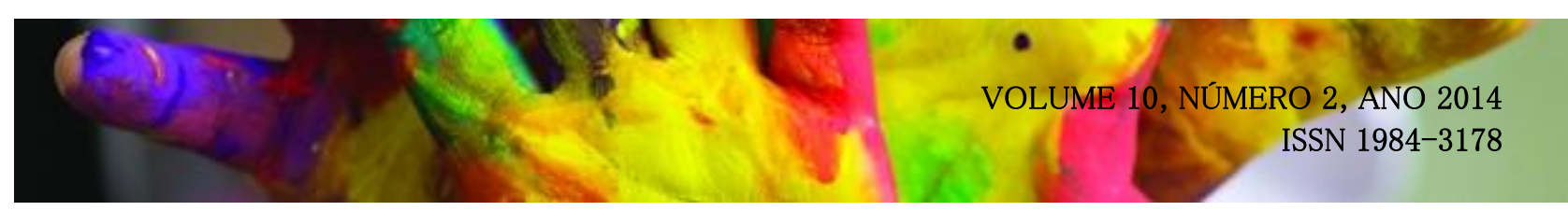

informações sobre os temas/assuntos abordados, pois trabalhamos com a ideia de hipertexto, por esse motivo disponibilizaremos diversos links para que ele possa escolher seus próprios caminhos. Segundo Barreto (2009) o hipertexto ${ }^{6}$ é uma rede de associações, pois nenhum texto começa e termina nele mesmo, pois um texto sempre dialoga com outros, assim como remete a possibilidade de outros tantos. Ele é uma forma de intertextualidade explícita. Sendo que o hipertexto on-line acontece através de links proporcionando o conhecimento em rede.

(1) Fotografia: esta permite uma infinidade de atividades, apresentaremos algumas: é possível criar trabalhos abordando a história da fotografia, assim como a construção de câmera pinhole $e^{7}$; apresentar obras do artista Vik Muniz ${ }^{8}$ e a ideia de 'obra momentânea', a qual só sobrevive através do registro fotográfico; ensinar perspectiva através da fotografia, ou seja, proporção por meio de distâncias através da relação existente entre pessoa/pessoa e pessoa/objeto ${ }^{9}$. Um exemplo de atividade com fotografia: os alunos do $9^{\circ}$ ano realizaram roupas de papel com base no trabalho do artista contemporâneo Jum $\mathrm{Nakao}^{10}$ e tiraram várias fotografias (com direito a poses de modelos, análise de imagens em revistas, problematização da indústria cultural ${ }^{11}$ e manipulação de imagens ${ }^{12}$ ) e até produção de um vídeo do desfile dos alunos vestindo as roupas criadas. Recomendamos o site do Itaú Cultural na parte que trata sobre fotografia de uma forma dinâmica e interativa com o tema: "Isto é uma foto?" ${ }^{13 ،,}$ esse site também proporciona diversas atividades.

\footnotetext{
6 Segundo Barreto (2009) os hipertextos multimidiáticos articulam linguagem verbal, sonora e imagética. Após o cinema, televisão e a tecnologia digital, esse universo audiovisual se ampliou, favorecendo a circulação de "textos" tecidos pela articulação das múltiplas linguagens.

7 Câmera fotográfica pinhole de lata, disponível em: http://www.youtube.com/watch?v=Xt3Cdq0qOns Acesso em: $15 / 06 / 2014$.

8 Site do artista Vik Muniz, disponível em: http://vikmuniz.net/pt/ Acesso em: 19/06/2014.

9 Para ver dicas de como trabalhar com "Fotografia: como criar ilusões com perspectiva", veja o texto escrito por Ana Nemes (2011), disponível em: http://www.tecmundo.com.br/12400-fotografia-como-criar-ilusoes-com-perspectiva.htm Acesso em: 10/06/2014.

${ }^{10}$ Vídeo Jum Nakao - Desfile, disponível em: http://www.youtube.com/watch?v=iEuTgRiOKzQ Acesso em: $18 / 06 / 2014$.

11 Exemplo sintético, disponível em: http://www.youtube.com/watch?v=OcsQP8uLQkc Acesso em: 12/06/2014.

12 Exemplo de manipulação de imagem (1), disponível em: http://www.youtube.com/watch?v=iYhCn0jf46U Acesso em: 05/06/2014. Exemplo de manipulação de imagem no vídeo (2), disponível em: http://awebic.com/pessoas/ditadurada-beleza/ Acesso em: 10/06/2014.

13 Disponível em: http://www.itaucultural.org.br/fotografia/07.html Acesso em 13/06/2014.
} 


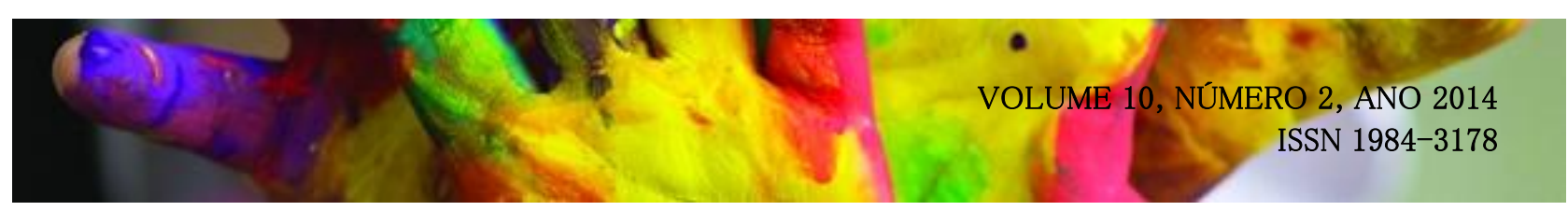

(2) Cinema: o professor pode propor atividades abordando o "pré-cinema" (brinquedos ópticos) $)^{14}$; apresentar os primeiros filmes realizados; analisar os efeitos especiais, enquadramentos, montagens, ângulos (dos filmes atuais/antigos, comerciais e/ou cult), etc; Como exemplo: os alunos do $1^{\circ}$ ano do Ensino Médio realizaram alguns brinquedos ópticos em grupo e depois produziram um curta (utilizando filmadora), baseado nas características do Expressionismo Alemão, sobre alguma lenda da cidade, do bairro ou da própria escola. Eles usaram lanterna, baixaram trilha sonora da internet, organizaram o cenário e o figurino, fizeram um roteiro, filmaram e depois mostraram para a turma os vídeos produzidos e um comentou/analisou o trabalho do outro.

(3) Vídeo-arte: no que se refere a vídeo-arte é possível mostrar trabalhos de artistas contemporâneos, tais como: Bill Viola ${ }^{15}$, Peter Campus ${ }^{16}$, Letícia Parente ${ }^{17}$, entre muitos outros artistas; vídeos que abordem a diversidade cultural tal como: "Vídeo-arte Movimento Étnico."18 Depois, ou antes, fica a critério do professor, pedir para os alunos se organizarem em grupos e pensarem num problema a ser representado na forma de imagem em movimento. Por exemplo, uma aluna do $3^{\circ}$ ano do Ensino Médio realizou um vídeo, no qual só apareciam as mãos dela segurando diferentes materiais, tais como: plástico bolha, sulfite amassado, esponja de lavar louça, etc. A primeira impressão era que o som do vídeo pertencia ao material apresentado, após um tempo de observação era possível perceber que os sons não tinham ligação direta, pois eram sons que foram manipulados no computador e não os sons dos objetos. Outra dupla de alunos, também do $3^{\circ}$ ano do Ensino Médio, realizou um vídeo sobre a impossibilidade da comunicação oral, onde eles usaram um prato transparente com um pouco de água e ficaram "falando", só que não se ouvia nada (apenas víamos a articulação das palavras e as bolhas d'água) e o outro respondia da mesma forma.

(4) Stop motion: Essa técnica une fotografia e vídeo. Com esse trabalho é possível mostrar aos

\footnotetext{
14 História do pré-cinema - brinquedos ópticos, disponível em: http://precinema.wordpress.com/2009/10/28/brinquedos-opticos/ Acesso em 19/06/2014.

${ }^{15}$ Vídeo-arte de autoria do Bill Viola - "Acceptance", disponível em: http://www.youtube.com/watch?v=UJQmV8aPNao Acesso em 13/06/2014 e "White Space”, disponível em: http://www.youtube.com/watch?v=pI5U5bapHcw Acesso em: 13/06/2014.

${ }^{16}$ Vídeo-arte de autoria do Peter Campus - "Three Transitions", disponível em: http://www.youtube.com/watch?v=Ar99AfOJ2o8 Acesso em: 15/06/2014.

${ }^{17}$ Vídeo-arte de autoria da Letícia Parente - "Marca registrada", disponível em: http://www.youtube.com/watch?v=atO9tsBUjVM Acesso em: 15/06/2014.

${ }^{18}$ Disponível em: http://www.youtube.com/watch?v=BKQ3Gx_BGGo Acesso em: 17/06/2014.
} 


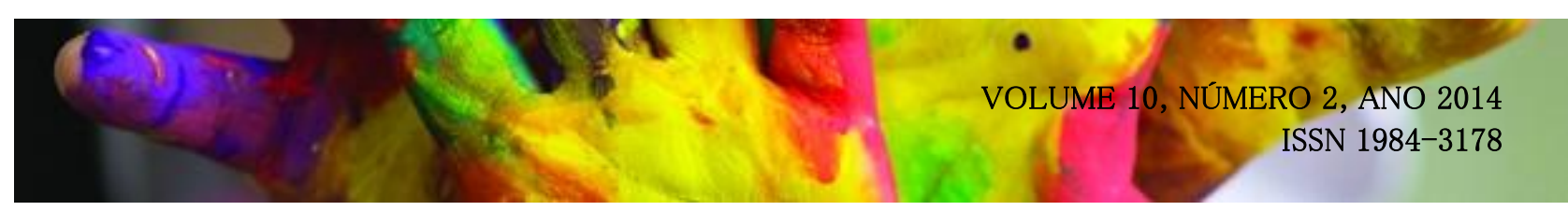

alunos o princípio da imagem em movimento e comentar sobre a percepção do olho humano. Também é possível trabalhar com o próprio corpo, com massinha de modelar, com desenho sequencial, objetos, entre outros. Sugerimos, num primeiro momento, que se trabalhe com objetos, pode ser lápis, borracha, algum chaveiro, enfim objetos que os alunos têm a mão e pode-se usar o próprio celular com câmera fotográfica. Como exemplo: a autora buscava cuidar do 'fundo', fixar a câmera, pois o que precisa se mover são os objetos não o celular ou a máquina fotográfica, e pedia para os alunos, em grupo, realizarem uma sequência de 15 fotos. Às vezes no próprio celular já era possível ver o movimento através de imagens sequenciais. Após essa primeira experimentação, a autora pedia aos alunos a criação de algo com uma narrativa ou intenção, usando qualquer um dos meios acima citados. Três alunas do $7^{\circ}$ ano resolveram experimentar materiais, usando bexigas coloridas (enchendo e esvaziando), guarda-chuva (abrindo e fechando), roupas dobradas (pilha aumentando e diminuindo). Quatro alunos de uma turma do $9^{\circ}$ ano preferiram usar massinha de modelar, eles construíram um cenário numa caixa de papelão, criaram uma pequena história sobre um homem que morria atropelado e virava um anjo (usaram fio de nylon para fazer o anjo ir subindo - saindo do cenário - até desaparecer). O programa utilizado para realizar essas animações foi o Movie maker, pois ele é de fácil manipulação. Indicamos o plano de aula denominado "Como fazer animações stop-motion" presente na Revista Nova Escola ${ }^{19}$ para quem desconhece essa técnica e vídeos no youtube ${ }^{20}$ com exemplos de animações.

(5) Museus virtuais: as possibilidades de atividades utilizando a internet são inúmeras, por isso faremos um recorte e apresentaremos apenas os museus visuais. Nem sempre o professor tem oportunidade de levar os alunos para visitar o espaço físico de um museu. Os motivos vão desde questões burocráticas e financeiras até não ter museus próximos das escolas. No entanto, com a internet e a possibilidade de visitar museus do mundo todo virtualmente, os alunos podem conhecer além da obra (que ele vê reproduzida num tamanho padronizado no Datashow ou na "TV

\footnotetext{
19 Disponível em: http://revistaescola.abril.com.br/fundamental-2/como-fazer-animacoes-stop-montion-643173.shtml Acesso em: 10/06/2014.

${ }^{20}$ Vídeo com noções gerais sobre animação (sintético) - “Animação Stop Motion”, disponível em: http://www.youtube.com/watch?v=IfY3ONW-yWw Acesso em: 10/06/2014;

Vídeo com exemplo de animação bem elaborado - "Western Spaghetti by PES”, disponível em: http://www.youtube.com/watch?v=qBjLW5_dGAM Acesso em: 10/06/2014;

Vídeo com exemplo de animação mais simples - "Borboleta de massinha em stop motion", disponível em: http://www.youtube.com/watch?v=OgWINgV5D_M Acesso em: 10/06/2014.
} 


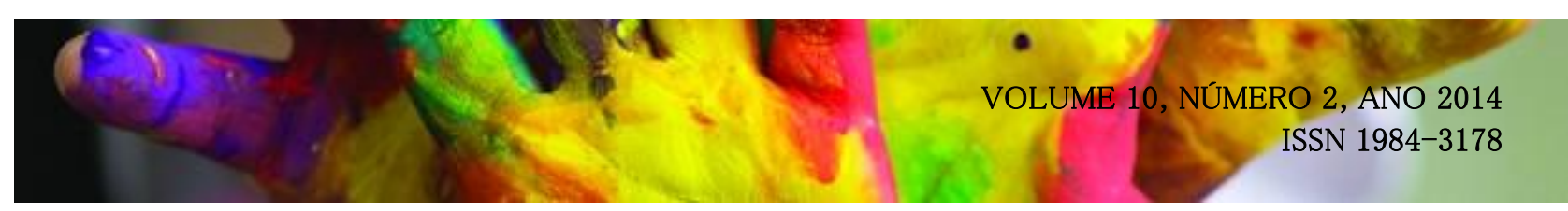

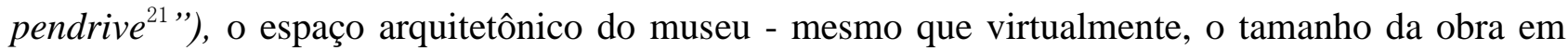
relação a esse espaço e escolher como "andar" dentro do museu, isso possibilita mais autonomia para o aluno. Indicamos o site sobre museus virtuais do "Laboratório de Ensino de História do Recôncavo da Bahia (UFRB)”,22, o qual disponibiliza vários links de sites de museus brasileiros e estrangeiros, entre eles o "Museu Casa Portinari. ${ }^{23 "}$ Também existe o "Projeto Era Virtual Museus" ${ }^{24}$ que apresenta vários links para museus de diversos estados brasileiros. Recomendamos uma visita virtual na exposição “A magia de Escher" (2013) e a outras exposições realizadas no Museu Oscar Niemeyer ${ }^{25}$, localizado em Curitiba (PR); no Museu do Louvre ${ }^{26}$ e na Capela Sistina $(\text { Vaticano })^{27}$, entre muitos outros.

(6) Redes sociais: a autora participou de um evento intitulado "Aulas Conectadas" realizado pela FAED/UDESC no ano de 2013 e neste evento teve a oportunidade de ouvir o relato de experiência de uma professora de geografia que trabalhou os conteúdos de sua área utilizando as redes sociais. Segundo essa professora, os alunos foram divididos em grupos e cada um escolheu um tema polêmico para criar uma espécie de campanha usando o "Facebook". Os temas foram bem variados, dentre eles destacamos: "luta contra o câncer" e "violência contra a mulher". Os alunos precisavam (i) criar páginas na rede social, símbolos, selecionar imagens, fazer entrevistas, convidar professores e a comunidade em geral para participar, tudo isso utilizando uma rede social. Os alunos também podiam organizar grupos de estudos, passeatas e após o término da atividade proposta pela professora podiam (ii) criar sites $^{28}$ e/ou blogs e dar continuidade ao projeto.

Como essa experiência poderia ser utilizada nas aulas de Arte? Talvez os alunos pudessem escolher artistas para mostrar obras, fazer entrevistas com artistas da sua cidade, procurar links de museus para visitar e publicar imagens que encontrassem nos acervos dos museus, discutir "o que é

\footnotetext{
21 "TV pendrive" são televisões que foram disponibilizadas para as escolas/salas de aula no Estado do Paraná.

${ }^{22}$ Disponível em: http://www.ufrb.edu.br/lehrb/sites-apoio-ao-professor/objetos-digitais-ensino-historia/museusvirtuais/ Acesso em: 12/06/2014.

${ }^{23}$ Disponível em: http://museucasadeportinari.org.br/vrt/index.html Acesso em: 11/06/2014.

${ }^{24}$ Disponível em: http://www.eravirtual.org/pt/ Acesso em: 12/06/2014.

${ }^{25}$ Disponível em: http://www.tourvirtual360.com.br/mon/escher/flash/index_escher.html Acesso em: 12/06/2012.

${ }^{26}$ Disponível em: http://www.louvre.fr/en/visites-en-ligne Acesso em: 12/06/2014.

${ }^{27}$ Disponível em: http://www.vatican.va/various/cappelle/sistina_vr/index.html Acesso em:12/06/2014.

${ }^{28}$ Recomendamos os seguintes sites para criação de blogs e sites: "WIX", disponível em: http://pt.wix.com/ Acesso em: 12/06/2014. E o “Wordpress", disponível em: https://br.wordpress.com/ Acesso em: 12/06/2014.
} 


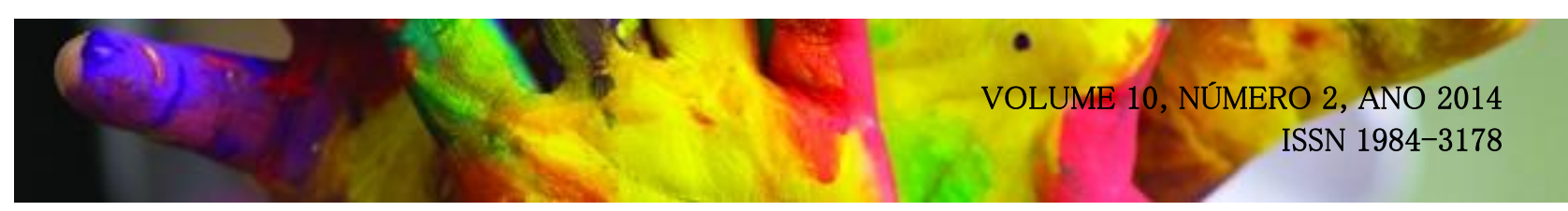

arte?" através, principalmente, de imagens/vídeos de arte contemporânea, e também produzir/trocar/compartilhar/divulgar seus próprios trabalhos artísticos.

(7) Programas de manipulação e criação de imagens: Os alunos, principalmente os adolescentes, costumam tirar muitas fotos e postar em redes sociais. Pensando nisso, o professor poderia trabalhar o autorretrato, mostrando obras de artistas, tais como: Frida Kahlo, Van Gogh, Cindy Sherman, etc. E trabalhar a própria imagem produzida pelos alunos, desde a distorção/multiplicação até um refinamento e melhoramento da imagem. Sugerimos alguns programas que podem ser utilizados para essa finalidade: Paint, Microsoft Office Picture Manager, PhotoScape ${ }^{29}$, Gimp, Photoshop ${ }^{30}$, etc. É importante lembrar que muitas vezes os próprios alunos costumam utilizar e conhecem vários programas para edição de imagens. Essa pode ser uma boa oportunidade para o professor trocar informações e aprender com eles.

(8) Aplicativos: A autora ainda não está muito familiarizada com os aplicativos, porém como alguns professores entrevistados afirmaram que utilizam os mesmos na sala de aula, apontaremos alguns links de aplicativos ${ }^{31}$ para quem tiver interesse em pesquisar mais. Existem diversos tipos de aplicativos, entre eles o Scrap book ${ }^{32}$, jogos digitais de artistas, etc. Sugerimos que o professor peça para os alunos pesquisarem aplicativos sobre arte, pois como eles, em geral, conhecem muitos, acreditamos que eles poderão ter mais facilidade para encontrá-los.

Após essas considerações, indicações e exemplos de atividades abordando as novas tecnologias e as Artes Visuais, esperamos que o professor que ainda não realizou nenhuma atividade semelhante, experimente, pesquise e crie aulas explorando algumas dessas atividades e para os professores que conhecem bastante esse assunto e realizaram trabalhos distintos, que auxilie os outros docentes publicando suas experiências na sala de aula. Assim, poderemos crescer juntos e proporcionar um ensino de arte em consonância com as exigências do mundo contemporâneo e mais atrativo/significativo para os nossos alunos.

\footnotetext{
${ }^{29}$ Também é possível produzir Gifs animados com esse programa.

${ }^{30}$ Exemplo de uma intervenção utilizando o photoshop, disponível em: http://www.youtube.com/watch?v=BRAM8MpqIeA Acesso em 05/06/2014.

${ }^{31}$ Exemplos, disponível em: http://www.tecnoartenews.com/tag/app-2/ Acesso em: 18/06/2014.

${ }^{32}$ Exemplo disponível em: http://www.baixaki.com.br/download/craftartist-compact.htm Acesso em: 15/06/2014.
} 


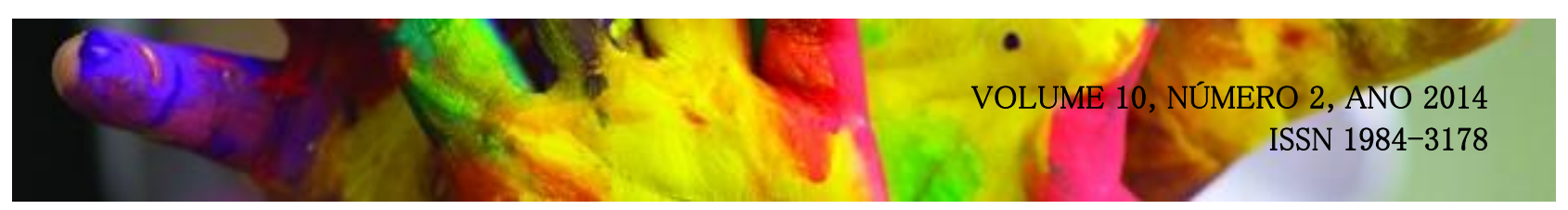

\section{CONSIDERAÇÕES FINAIS}

Com base no exposto vemos que é possível utilizar as novas tecnologias nas aulas de arte, apesar das dificuldades. Vimos que alguns obstáculos apresentados referem-se à infraestrutura e a própria formação do professor. Hoje, existem muitos cursos on-line gratuitos ${ }^{33}$ e informações disponíveis sobre Tecnologia na Educação ${ }^{34}$, nos quais o professor pode buscar apoio. E os próprios alunos podem auxiliar na questão do uso das novas tecnologias.

Se faz necessário, também, rever alguns pontos da formação inicial no que se refere às novas tecnologias, tais como: proporcionar aos licenciandos contato real com esses novos meios na sua produção acadêmica e propor atividades abordando as novas tecnologias no estágio, para que o futuro professor se familiarize com as mesmas no processo de ensino-aprendizagem de arte. Também é preciso maior investimento na formação continuada para que o docente possa adquirir/conhecer ainda mais as novas tecnologias e pensar nelas como aliadas do ensino da arte.

Quanto à infraestrutura, sabemos que os problemas são vários, porém, sempre que possível é importante introduzir atividades que contemplem as novas tecnologias para ampliar o horizonte do aluno, conscientizá-lo do uso desses meios, fazer com que ele fique "conectado" com o mundo contemporâneo e conheça novas formas de produzir trabalhos artísticos com base em materiais que muitos deles já utilizam no cotidiano.

Esperamos que os exemplos de atividades fornecidos, assim como o relato dos professores entrevistados no Estado de Santa Catarina, motivem outros professores a escrever sobre sua prática docente e a buscar mais informações sobre como utilizar as novas tecnologias no ensino de arte.

\footnotetext{
${ }^{33}$ Curso online gratuito, com direito a certificação, tal como: "Novas Tecnologias para a aprendizagem no Ensino médio e Fundamental". Disponível em: http://www.apoioaoprofessor.com.br/novas-tecnologias-para-a-aprendizagem-noensino-medio-e-fundamental-faca-a-sua-matricula-gratuita/ Acesso em 20/06/2014.

${ }^{34}$ Revista Nova Escola - Tecnologia na Educação: as melhores ferramentas e as novidades sobre o uso das TIC (tecnologia da informação e comunicação) na sala de aula, disponível em: http://revistaescola.abril.com.br/blogs/tecnologiaeducacao/?utm_source=redesabril_fvc\&utm_medium=facebook\&utm_ campaign=redesabril_novaescola Acesso em: 10/06/2014.
} 


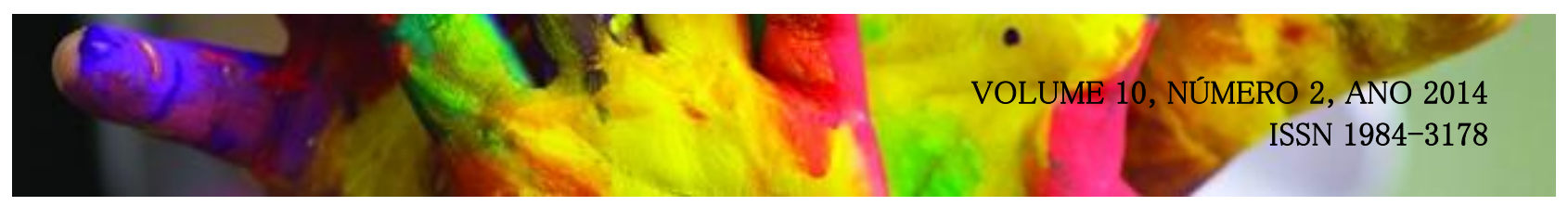

\section{REFERÊNCIAS}

Barreto, Raquel Goulart. Discursos, Tecnologias, Educação - Rio de Janeiro: EdUERJ, 2009.

BERTOLETTI, Andréa. Tecnologias digitais e o ensino da arte: algumas reflexões. Anais do V Ciclo de Investigações do PPGAV - UDESC, 2010. Disponível em: http://ppgav.ceart.udesc.br/VCiclo/artigo05.pdf Acesso em: 11/05/2014.

BRASIL. MEC. Conselho Nacional de Educação/ Câmara de Educação Superior. Parecer homologado: Diretrizes Curriculares Nacionais do Curso de Graduação em Artes Visuais, bacharelado e licenciatura. Distrito Federal. 2007. Disponível em: http://portal.mec.gov.br/cne/arquivos/pdf/2007/pces280_07.pdf Acesso em: 11/05/2014.

BRASIL. MEC. Secretaria de Educação Fundamental. Parâmetros Curriculares Nacionais: arte. Brasília, SEF/MEC, 1998. Disponível em: <http://portal.mec.gov.br/seb/arquivos/pdf/arte.pdf > Acesso em: 29/04/2014.

LOYOLA, Geraldo Freire. me adiciona.com - Ensino da arte + Tecnologias contemporâneas + Escola pública. Dissertação de mestrado. Belo Horizonte, UFMG, 2009. Mestrado em Artes. Disponível em: http://www.bibliotecadigital.ufmg.br/dspace/bitstream/handle/1843/JSSS7WSQ3H/me_adiciona_com_ensino_de_arte_tecnologias_contempor_neas_escola_p_blica.pdf?seq uence $=1$ Acesso em: 12/06/2014.

MARTINS, Alice Fátima. Novas Tecnologias e o Ensino das Artes Visuais: algumas considerações. Disponível em: http://www.anpap.org.br/anais/2007/2007/artigos/063.pdf Acesso em: 16/06/2014.

PIMENTEL, Lucia Gouveia. Novas territorialidades e identidades culturais: o ensino de arte e as tecnologias contemporâneas. Anais da ANPAP, pp.765-771. Disponível em: http://www.anpap.org.br/anais/2011/pdf/ceav/lucia_gouvea_pimentel.pdf Acesso em: 13/06/2014. SANTAELLA, Lucia. As imagens no contexto das estéticas tecnológicas. Brasília, 2007. Disponível em: http://www.arte.unb.br/6art/textos/lucia.pdf Acesso em: 12/06/2014. 